
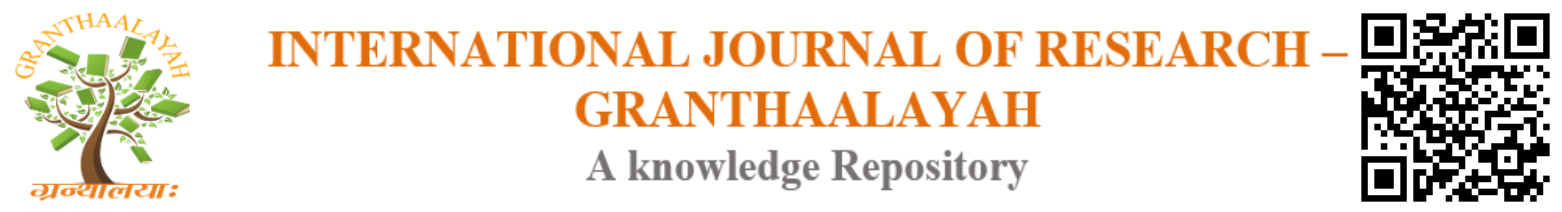

Science

\title{
BLINDNESS AND REHABILITATION CONCERNS AMONGST PUPILS OF A SPECIAL EDUCATION CENTRE IN SOUTHWESTERN NIGERIA
}

\author{
Dr. Jagun O.O *1, Dr. Akinola M.A ${ }^{2}$, Dr. Betiku O.O ${ }^{3}$, Dr. Salami O.F ${ }^{4}$ \\ ${ }^{* 1}$ MBCHB, FMCOph, Department of Surgery, Babcock University, Nigeria \\ ${ }^{2}$ MBBS, FMCORL, Department of Surgery, Babcock University, Nigeria \\ ${ }^{3}$ MBBS, FWACS, Department of Surgery, Babcock University, Nigeria \\ ${ }^{4}$ MBCHB, FMCA, Department of Surgery, Babcock University, Nigeria
}

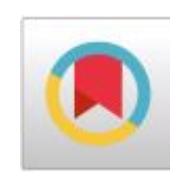

\begin{abstract}
Background: Blind Children require access to quality rehabilitation services to optimize function and reduce their disabilities. This may be difficult if competent educators are not available in special education centers in developing countries.

Method: A prospective study carried out on consenting parents and pupils at a special education center in South western Nigeria.

Results: Sixty-two blind eyes from 31 participants were examined. 25.8\% [16] had Optic atrophy, $16.1 \%$ [10] had complicated cataracts, $12.9 \%$ [8] had Cornea related blindness, 9.7\% [6] had End stage Glaucoma, another 9.7\% [6] had Phthisis bulbi while the last $25.85 \%$ [16] were classified as Others. $94.1 \%$ of the educators had undergone Special educational training over the last 20 years but only $11[64.7 \%]$ had attended any refresher course over the last 5 years to update theirs teaching skills and only $11.8 \%$ had easy access to Online study materials for research and training. Academic skills were taught by all teachers with all students being able to read and write in Braile but recreational skills were least taught in the school.

Conclusion: A need for strong Governmental and Non-governmental advocacy to support training of Special educators and to integrate parental education in the Rehabilitation process.

Keywords: Blindness; Rehabilitation; Disability; Educators; Education.

Cite This Article: Dr. Jagun O.O, Dr. Akinola M.A, Dr. Betiku O.O, and Dr. Salami O.F. (2019). "BLINDNESS AND REHABILITATION CONCERNS AMONGST PUPILS OF A SPECIAL EDUCATION CENTRE IN SOUTHWESTERN NIGERIA.” International Journal of Research - Granthaalayah, 7(4), 365-370. https://doi.org/10.29121/granthaalayah.v7.i4.2019.922.
\end{abstract}

\section{Introduction}

Normal vision is defined as Visual acuity of 20/20 while blindness is Vision worse than 20/100 after the best correction ${ }^{1}$. According to $\mathrm{WHO}$, two hundred and eighty-five million people have visual impairment globally, 246 million have low vision and 39 million blind ${ }^{2} .18 .9$ million of 
those with visual impairment are between the ages of $0-14$ years with 1.4 million being irreversibly blind and require access to rehabilitation services to optimize function and reduce their disability ${ }^{2}$. Global statistics on the causes of childhood blindness according to the descriptive classification by World bank regions has shown diverse variations ${ }^{3}$. The Established market economies have their major causes of blindness being related to the Retina (25\%), Optic nerve (25\%), Central nervous system (10\%) and the Lens (8\%). While regions in Sub Sahara Africa have documented mainly Cornea (36\%), Retina (20\%), Optic nerve (16\%), Lens (9\%) and Globe (9\%) related causes ${ }^{3}$.

Ezegwui et al in South east Nigeria found that the major causes of blindness in children were related to the lens $(30.4 \%)$, cornea lesions $(21.7 \%)$, whole globe involvement eg Phthisis bulbi $(17.4 \%)$, and Congenital glaucoma $(10.9 \%)^{4}$. Ajibode et al also documented that corneal pathology $(57.1 \%)$ and Cataract related causes $(14.3 \%)$ were the main causes of blindness in students in Ogun State $^{5}$.

Basic human rights ensure that persons with disabilities are not excluded from the general education system on the basis of disability and that persons with disabilities receive the support required within the general education system to facilitate their effective education ${ }^{6}$ but lack of available modern instructional facilities and educational funding for disabled children has been a major source of concern for educators ${ }^{7}$ in Nigeria.

Rehabilitation is the process designed to assist the 'injured child' who is experiencing or likely to experience disability to achieve and maintain optimal function in their interactions with the environment ${ }^{8}$.

Rehabilitation of the visually impaired child is addressed by the nine components of the Expanded Core Curriculum (ECC) which includes Compensation of functional skills, Orientation and mobility, Social interaction skills, Independent living, recreation and leisure, Carrier education, Technology, sensory efficiency and self-determination which are used as a frame work for planning individual goals for the visually impaired child. ${ }^{8}$ This study aims to determine the aetiology of blindness and assess rehabilitation challenges amongst children attending a Special Education center in Ogun State.

\section{Materials and Methods}

This is a prospective study using the WHO/PBL examination form for the visually impaired and blind $^{9}$, which was modified to fit the study setting alongside a questionnaire completed by parents/ care givers of the students.

Target population were all enrolled students at The Ade Okubanjo model school for the visually challenged children, Ijebu-Igbo, Ogun State, which is a boarding school. The study was carried out over a period of 4 months between July and October 2017.

Only 51 out of 85 students on the enrolment register were available during the first school visit, and they were given the study protocol and consent forms to take home during the preceding holiday, while those who returned with a written parental consent were included in the study. 
Students with mental retardation and those who refused to participate were excluded from the study.

Ethical approval was received from the Babcock University Review Ethical Committee and further written permission obtained from the Ogun State Ministry of Education and The Ogun State Ministry of Education.

Data analysis was done using SPSS verson 21.

\section{Results and Discussions}

Thirty one out of fifty-one students obtained the required parental consent and participated in the study. Age range of participant was between 8 years to 28 years, with a mean of $16.9 \pm 6.1$ years. Forty percent (34 out of 85 ) of the students on the school's enrolment register were away from school for various reasons.

Twenty $(64.6 \%)$ of the fathers indicated attending at least secondary school but there was no evidence of completion of the secondary, while 23 (74.2\%) of the mothers/care givers also had some form of secondary school education. Occupational status of parents is shown in Table 1.

Table 1: Parents occupational status

\begin{tabular}{|lcc|}
\hline Occpation & Fathers & Mothers/Care givers \\
\hline & Number [ \%] & Number [\%] \\
\cline { 2 - 3 } Artisans & $12[38.7]$ & $6[19.4]$ \\
Self employed & $10[32.3]$ & $18[58.0]$ \\
Civil servants & $6[19.4]$ & $6[19.4]$ \\
No Response & $3[9.6]$ & $1[3.2]$ \\
\hline Total & $\mathbf{3 1}[\mathbf{1 0 0}]$ & $\mathbf{3 1}[\mathbf{1 0 0}]$ \\
\hline
\end{tabular}

$25(80.6 \%)$ of the students were delivered in the hospital while $6(19.4 \%)$ were delivered in nonorthodox settings like religious homes and traditional birth centres. 93.5\% (29) were products of full-term delivery and $96.8 \%$ were spontaneous vaginal delivery.

Only $12.9 \%$ (4) of the students were said to have shown any abnormal ocular symptoms (mainly jaundice) noticed at birth, 22.6\%(7) developed poor vision before the age of one, $25.8 \%$ (8) between one and age five while $38.7 \%$ (12) developed after age five.

All participants were blind with visual acuities ranging from Hand motion to Nil light perception. A total of 62 eyes from 31 participants were examined. 25.8\% [16] had Optic atrophy, 16.1\% [10] had complicated cataracts, $12.9 \%$ [8] had Cornea related blindness, 9.7\% [6] had End stage Glaucoma, another 9.7\% [6] had Phthisis bulbi while the last 25.85\%[16] were classified as Others and were blind from Retinitis pigmentosa, Retinal detachment, Ocular burns and Empty socket.

Seventeen teachers, out of which 10 [58.8\%] are males, teach in the school. Sixteen [94.1\%] had undergone Special educational training over the last 20 years but only $11[64.7 \%]$ had attended any course over the last 5 years to update theirs teaching skills. Only 2 [11.8\%] of the teachers had 
easy access to Online study materials for research and training. The skills taught by these teachers according to the Expanded Core Curriculum (ECC) is shown in Table 2.

Most parents (90.3\%) felts their children were getting good educational training in the school, even though they were not sure of the required curriculum but some $(32.3 \%)$ still wanted improvement in the students' Academic content while 48.4\% wanted improvement in the available accommodation and learning facilities of the school.

Table 2: Educational skills taught by the school teachers

\begin{tabular}{|lll|}
\hline Skills Required & If Taught by teachers & Not Taught by teachers \\
\hline 1.Academic & $17[100 \%]$ & - \\
2.Orientation & $11[64.7 \%]$ & $6[35.3 \%]$ \\
3.Social & $16[94.1 \%]$ & $1[5.9 \%]$ \\
4.Independent living & $13[76.5 \%]$ & $4[23.5 \%]$ \\
5.Recreational & $8[47.1 \%]$ & $9[52.9 \%]$ \\
6.Assistive technology & $12[70.6 \%]$ & $5[29.4 \%]$ \\
7.Sensory & $11[64.7 \%]$ & $6[35.3 \%]$ \\
8.Self determination & $10[58.8 \%]$ & $7[41.2 \%]$ \\
9.Career & $12[70.6 \%]$ & $5[29.4 \%]$ \\
\hline
\end{tabular}

\section{Discussion}

The International Agency for the prevention of blindness under the VISION 2020 global initiative have been collaborating with different agencies to promote avoidable blindness ${ }^{10}$ and even extend eyecare to the blind globally.

In this study, all eyes examined were blind with Optic nerve related disease $(35.8 \%)$ being the most prevalent cause, followed by lens issues which were mainly due to complicated cataracts (16.1\%) and cornea disease (12.9\%) while those classified as others (28.85\%) included Phthisis bulbi, Retinitis pigmentosa (RP), Retinal detachment (RD), Ocular burns and empty socket. This pattern is however different from what was seen in the same State in 1996 where Cornea related causes were the most prevalent $(39.3 \%)$, followed by lens related causes $(14.3 \%)$ and RP $(7.1 \%)^{5}$. Complicated or poorly managed paediatric cataracts and poor immunisation guidelines/ compliance by mothers could have been the major cause of blindness in this same environment fifteen years earlier 5 .

There was no documented case of retinopathy of prematurity as all the students were born at term and the high prevalence of Optic nerve related disease were mainly due to congenital optic nerve diseases including glaucoma. Blindness from some of these diseases could have been prevented if diagnosed and treated prompt ${ }^{11}$ as documented that about $80 \%$ of children who had prompt surgical intervention for congenital glaucoma had moderate to normal vision of 20/200 to 20/20 after 21 years follow up ${ }^{11}$.

Blindness in a child, affects the whole family and their society negatively and this disability when estimated from the Disability Adjusted Life Years (DALY) has been described as a major cause of burden with a global lost capacity of between six to twenty-seven Million dollars ${ }^{12}$. 
Appropriate rehabilitation of the blind child would drastically reduce this burden as these individuals would be able to live independent lives. The ECC is the usual curriculum used for the blind children but the lack of updated training of the educators may undermine the potentials of the blind child ${ }^{12}$.

Most teachers were noted to teach the 9 components of the ECC but the parents were not aware of the curriculum expected to be covered by their children. Academic skills were taught by all teachers with all students being able to read and write in Braile but recreational skills were least taught in the school, this may be because most of the teachers themselves were blind and also had limited educational facilities ${ }^{13}$ thus making this skill difficult to learn and teach. Personal interview of some of the parents and teachers, revealed that most parents were just glad they had somewhere to put these physically challenged children and some of the parents don't even bother to find out about the wellbeing of their child throughout the school session.

The positive role of parents in the successful rehabilitation of these students cannot be over emphasized, as they can further help to evaluate the school programs and report the progress noticed in their children. ${ }^{14}$ But if the parents are not enthusiastic about bringing the blind students to school as seen in this study where $40 \%$ of the students were out of school, this becomes a problem. Parents have also been encouraged to partner in the rehabilitation of their children by forming support groups amongst themselves and serve as advocacy to also educate the public on preventable disabilities ${ }^{14}$.

\section{Conclusions and Recommendations}

There is a need for strong advocacy Governmental and Non-governmental agencies to support training and retraining of educators of the disabled so as to maximize their potentials. Structured policies to ensure parental participation in the rehabilitation process of the students should also be put in place.

\section{References}

[1] Low vision and legal blindness. https://www.afb.org (Accessed 20/03/2019)

[2] World Health Organization, Global data on Visual Impairments 2012. www.who.int/blindness/globaldatafinalforweb.pdf?ua=1 (Accessed 25/03/2019).

[3] Gilbert C. New Issues in Childhood blindness. Community Eye Health 2001; 14(40)

[4] Ezegwui I R, Umeh RE, Ezepue UF. Causes of childhood blindness: results from Schools of the blind in South eastern Nigeria. Br J Ophthalmol 2003; 87(1): 20-23.

[5] Ajibode H A, Onabolu O O, Oluyadi F O. Causes of blindness among blind students in Ogun State Nigeria. Nigerian Journal of Clinical practice 2003; 6(1): 17-19.

[6] Convention on the rights of persons with disabilities. United Nations. 2006. www.un.org>disabilities>conventionfull. Accessed 16/03/2019.

[7] Omede A.A. The use of assistive technology for persons with learning disabilities in special needs education in Nigeria. Research journal in organizational psychology and educational studies. 2012. Vol. 1(4): 261-265.

[8] Shanthi A, Alana O, Bliss T, Sandar T. Rehabilitation of the injured child. Bulletin of the World Health Organization 2009; 87:377.

[9] The standardized WHO/PBL eye examination form for the visually impaired and blind. Coding instructions for the WHO/PBL examination record version III. 
www.apps.who.int/iris/handle [ accessed 3/4/2019].

[10] World sight day 2019. https://www.awarenessdays.com. (Accessed 26/03/2019).

[11] Yassin SA. Long term visual outcomes in Children with Primary congenital glaucoma. Eur J Ophthalmol 2017; 27(6): 705-10.

[12] Gogate P, Kalua K, Courtright P. Blindness in Childhood in developing countries: Time for a reassessment? PLOS Med 2009;6 (12): e1000177

[13] Jagun Omodele, Onabolu Oluwatoni, Akinola Moses, Betiku Anthony, Oladeji Susan, Salami Omotayo. Evaluation of teachers in special education centres in Ogun State, Southwestern Nigeria. Transactions of the Ophthalmological society of Nigeria 2016; 1(1) :46-7

[14] Damayanto S, Pankaj B. Rehabilitation of children with special needs in India: Role of parents. GJRA- Global Journal for research analysis 2016: 5 (8):412-414.

\footnotetext{
*Corresponding author.

E-mail address: omodelly@yahoo.com
} 